\title{
LETRAMENTO EM QUÍMICA, EDUCAÇÃo PLANETÁRIA E INCLUSÃO SOCIAL ${ }^{*}$
}

\author{
Wildson Luiz Pereira dos Santos
}

Instituto de Química, Universidade de Brasília, CP 4478, 70910-970 Brasília - DF, Brasil

Recebido em 8/8/05; publicado na web em 16/2/06

\begin{abstract}
CHEMISTRY LITERACY, PLANETARY EDUCATION AND SOCIAL INCLUSION. From the different conceptions on scientific and technology literacy (STL), and reflections on globalization and social inclusion, this paper points out the responsibility of the chemists in social actions by their associations for supporting political actions to improving the quality of life, and to protecting the environment by sustainable development for changing the modern society. Supporting ideas for equity within the society between the nations, and giving examples from approaching of socioscientific issues of the textbook "Chemistry and Society", it demonstrated the role of the teachers and the chemistry professionals to realize the STL of the people in the planetary perspective.
\end{abstract}

Keywords: scientific and technology literacy; planetary citizenship; environmental education

\section{INTRODUÇÃO}

No mundo globalizado, podemos dizer que com exceção de tribos isoladas, todos os habitantes do planeta fazem uso diário de produtos químicos sintetizados pela indústria química e originados de conhecimentos químicos desenvolvidos por cientistas de todo mundo. A Química tem gerado empregos e desenvolvimento econômico, contribuindo de forma significativa para o aumento da qualidade de vida.

Apesar dos avanços científicos e tecnológicos que vêm dando respostas rápidas para muitos problemas ambientais, o modelo de desenvolvimento tecnológico que vem sendo adotado tem aumentado a concentração de renda, excluindo a maior parte da população global do acesso aos benefícios tecnológicos. Esse modelo de desenvolvimento tem priorizado o capital em relação às necessidades humanas. Isso tem resultado em um processo acelerado de degradação ambiental, com ocorrência de novas doenças que vêm afligindo enorme parte da população mundial e até mesmo ocasionando a morte imediata de milhares de pessoas em decorrência de grandes acidentes provocados por vazamento de gases, incêndios, contaminação de efluentes etc. A Química aparece nesse contexto, na maioria das vezes, como vilã, sendo poucas vezes lembrada pela população em geral como a responsável por muitos avanços no aumento, por ex., da expectativa de vida.

Nesse quadro, em que se socializam riscos e se elitizam benefícios, amplia-se o movimento de reivindicação de letramento científico e tecnológico para todos, por entidades populares, educadores, cientistas, empresários e governantes. Mas que significados cada um desses atores atribuem ao papel da alfabetização científica?

Discutindo diferentes concepções sobre letramento, apresentamos no presente artigo reflexões sobre o papel das sociedades científicas, dos profissionais da Química e, sobretudo, dos professores de escolas de educação básica, em relação ao compromisso de educação química em uma perspectiva planetária inclusiva, que assegure as conquistas da Química na melhora da qualidade de vida do Planeta Terra.

* Conferência proferida na $28^{\text {a }}$ Reunião Anual da Sociedade Brasileira de Química, Poços de Caldas, Brasil, 2005

*e-mail: wildson@unb.br

\section{LETRAMENTO CIENTÍFICO E TECNOLÓGICO}

Neste artigo, empregamos o termo letramento ao invés de alfabetização, adotando a versão para o Português da palavra inglesa "literacy", seguindo a tese de Soares ${ }^{1}$, que opta por usar esse termo e não a palavra alfabetização, conforme discutiremos mais adiante. $\mathrm{O}$ entendimento do significado de letramento em ciência e tecnologia - LCT - tem sido objeto de preocupação de diferentes atores sociais (Figura 1): comunidade de educadores em ciência; cientistas sociais; pesquisadores de opinião pública; sociólogos da ciência; e profissionais envolvidos na educação formal e não-formal em ciências, professores, jornalistas, profissionais de museus, centros de ciências, parques ambientais, jardins botânicos, zoológicos etc. O seu estudo está associado a pesquisas sobre compreensão pública da ciência, ciência para todos e educação em Ciência Tecnologia - Sociedade, CTS $^{2}$.

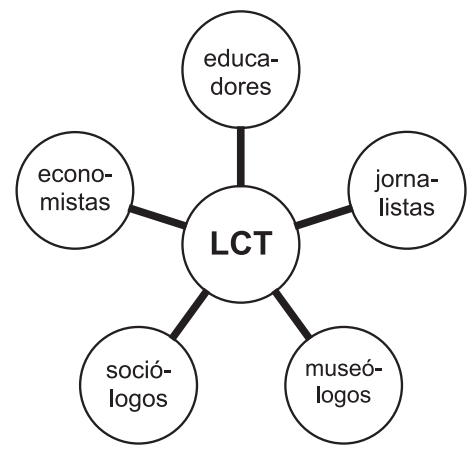

Figura 1. Alguns atores sociais interessados em letramento científico e tecnológico - LCT

Cada um desses profissionais tem enfoque diferente para os diversos contextos de LCT. Enquanto os educadores em ciência se preocupam com a educação no sistema formal de ensino; os cientistas sociais, com o interesse do público em geral por questões científicas; os sociólogos, com a interpretação diária da ciência; os comunicadores da ciência, com a divulgação científica em sistemas não-formais; e os economistas com o crescimento econômico decorrente do maior consumo da população por bens tecnológicos mais sofisticados, que requerem conhecimentos especializados, 
como o uso da informática. Os educadores em ciência buscam avaliar a aprendizagem em ciências; os sociólogos ocupam-se com pesquisas que medem o déficit de conhecimento público em ciências ou com estudos sobre como o público em geral usa o conhecimento científico com diferentes propósitos; já os economistas estão interessados na relação entre desenvolvimento econômico e nível de letramento da população, medidos pelo nível de escolarização².

Assim, diferentes atores sociais justificam o LCT com argumentos diferentes. Millar ${ }^{3}$, por ex., agrupa os argumentos usados para justificar a necessidade do letramento científico em cinco categorias: argumento econômico, que conecta o nível de conhecimento público da ciência com o desenvolvimento econômico do país; utilitário, que justifica o letramento por razões práticas e úteis; democrático, que ajuda os cidadãos a participarem nas discussões, no debate e na tomada de decisão sobre questões científicas; soci$a l$, que vincula ciência com cultura, fazendo com que as pessoas fiquem mais simpáticas à ciência e à tecnologia e, cultural, que tem como meta fornecer aos alunos o conhecimento científico como produto cultural. Conforme o interesse defendido por grupos profissionais ou comunidades escolares, serão atribuídas ênfases diferentes para os argumentos identificados por Millar.

Certamente, as diversas visões sobre as concepções de letramento científico implicam em modelos curriculares com ênfases em diferentes conteúdos. A perspectiva almejada em relação ao letramento determina o enfoque curricular em relação ao conteúdo científico. Se a prioridade do letramento for melhorar o campo de conhecimento científico, preparando novos cientistas, o enfoque curricular será centrado em conceitos científicos; se o objetivo for voltado para a formação do indivíduo, o enfoque será em conhecimentos práticos; e se a prioridade for direcionada para a função social, a ênfase será dada em atitudes e valores ${ }^{4}$.

A predominância da ênfase curricular no ensino de ciências propostas pelos educadores em ciência tem mudado em função de contextos sócio-históricos. No final da década de 1950, em plena guerra fria, com o lançamento do primeiro satélite artificial - o "sputinik", houve uma corrida pelos Estados Unidos para apressar a formação de cientistas, o que levou à elaboração de projetos curriculares com ênfase na vivência do método científico, visando desenvolver nos jovens o espírito científico ${ }^{5}$.

No final da década seguinte, com o agravamento de problemas ambientais, começou a surgir uma preocupação dos educadores em ciência por uma educação científica que tomasse em conta os aspectos sociais relacionados ao modelo de desenvolvimento científico e tecnológico. Esse movimento levou ao surgimento, no final da década de 1970, de propostas curriculares com ênfase nas interrelações em $\mathrm{CTS}^{6}$. Esses currículos com enfoque nas Ciências Sociais têm como objetivo central a formação de cidadãos que compreendam as interações entre os seus três componentes: ciência, tecnologia e sociedade.

Essas duas proposições históricas em relação ao papel de LCT, de certa forma, nos permitem sumarizar os enfoques que têm sido dados ao ensino de ciências nos últimos 40 anos em dois grandes propósitos: o de formação de cientistas ou especialistas e o de formação de cidadãos.

Em termos de formação de cientistas e especialistas, podemos tomar duas das três categorias de Laugksch ${ }^{2}$ sobre letramento: letramento como erudição e como competência. A categoria de letramento como erudição relaciona-se ao que Shamos ${ }^{5}$ classificou como letramento científico autêntico. Para Shamos ${ }^{7}$, esse envolve um conhecimento mais aprofundado dos construtos teóricos da ciência e da sua epistemologia, compreendendo os elementos da investigação científica, o papel da experimentação, o processo de elaboração dos modelos científicos. LCT, nessa perspectiva, consiste na formação técnica do domínio das linguagens e ferramentas mentais usadas em ciência para desenvolvimento científico e tecnológico. Para isso, os alunos devem ter amplo conhecimento sobre as teorias científicas e desenvolver competências e habilidades para propor modelos em ciência. Esse tipo de letramento exige o desenvolvimento de processos cognitivos de alto nível de elaboração mental de modelos explicativos para processos e fenômenos.

Se tomarmos letramento nessa acepção, podemos dizer que nossos alunos de graduação apenas iniciaram seu letramento científico pelo processo de aquisição de conhecimentos específicos sobre as teorias científicas da Química. Na realidade, temos dado muito pouca atenção para uma formação dos profissionais da Química, no sentido de compreenderem a epistemologia do conhecimento químico e desenvolverem habilidades cognitivas para adquirirem a forma de pensar a Química e buscar soluções para os seus problemas. Isso de certa forma, só vem sendo introduzido para os poucos alunos que participam de projetos de iniciação científica ou ingressam na Pós-graduação.

Com relação ao LCT destinado ao cidadão, Laugksch ${ }^{2}$ o define como capacidade mínima funcional para agir como consumidor $e$ cidadão. Isso para muitos autores se enquadra na categoria de Miller ${ }^{8}$, que corresponde à consciência e compreensão do impacto da ciência e tecnologia sobre a sociedade. Já DeBoer ${ }^{9}$ apresenta diversos propósitos para letramento, dos quais podemos considerar que se enquadram no letramento científico para o cidadão: o ensino - aprendizagem de ciências como uma força cultural no mundo moderno; a preparação para o mundo do trabalho; o ensino - aprendizagem de ciências que tem aplicação direta ao cotidiano; a preparação dos alunos para serem cidadãos informados; a aprendizagem de ciências como uma forma particular de examinar o mundo natural; a compreensão dos relatórios e discussões da ciência que aparecem na mídia; a aprendizagem de ciências por seus apelos estéticos; a preparação de cidadãos simpáticos à ciência e a compreensão da natureza e da importância da tecnologia e da relação entre tecnologia e ciência.

Shen ${ }^{10}$ inclui no LCT para o cidadão duas categorias: a prática e a cívica. A prática significa a "posse do tipo de conhecimento científico e técnico que pode ser imediatamente usado para ajudar a melhorar o padrão de vida das pessoas" (p. 265), que se relaciona com as necessidades humanas básicas de alimentação, saúde e habitação. A cívica refere-se ao conhecimento essencial que as pessoas necessitam para compreender as políticas públicas, visando preparar os cidadãos para atuarem na sociedade, quer compreendendo os processos relativos ao seu cotidiano e os problemas sociais vinculados à ciência e tecnologia, quer desenvolvendo competências que lhes permitam participar do processo de decisão sobre questões envolvendo saúde, energia, alimentação, recursos naturais, ambiente e comunicação.

Prewitt ${ }^{11}$ considera que o letramento científico para cidadão tem origem nas interações entre ciência e sociedade e promove o que ele chama de "cidadão prático": aquele que, apesar de não ser cientista ou tecnólogo, é capaz de atuar na sociedade em nível pessoal e social, compreendendo com perspicácia a profundidade dos princípios e estruturas que governam situações complexas, compreendendo como a ciência e a tecnologia influenciam sua vida.

Nesse contexto, o letramento dos cidadãos vai desde o letramento no sentido do entendimento dos princípios básicos de fenômenos do cotidiano até a capacidade de tomada de decisão em questões relativas à ciência e tecnologia em que estejam diretamente envolvidos, sejam decisões pessoais ou de interesse público. Esse letramento envolve, assim, a preparação do cidadão para ser capaz de fazer julgamentos críticos e políticos ${ }^{12}$.

LCT para cidadania, então, incorpora conhecimentos e compe- 
tências que habilitam o cidadão a tomar decisões pessoais que usem critérios com base em conhecimentos científicos, como por ex., na decisão sobre compra e utilização de novos equipamentos ou até mesmo sobre um tratamento médico, após ouvir diferentes especialistas. Esse letramento engloba a preparação do cidadão para se posicionar, por ex., em uma assembléia comunitária para encaminhar providências junto aos órgãos públicos sobre problemas que afetam sua comunidade em termos de ciência e tecnologia.

Há de se diferenciar, todavia, algumas concepções do que seria o real letramento do cidadão, ao que se restringe a um letramento superficial no sentido do domínio estrito vocabular de termos científicos. Aqui, podemos diferenciar o letramento do cidadão restrito a um enriquecimento como "ornamento cultural" daquele destinado a uma função social no sentido de participação do cidadão na sociedade.

Do ponto de vista escolar, podemos considerar que o letramento como "ornamento cultural" corresponderia ao processo restrito de alfabetização, que se diferencia do letramento propriamente dito, como vem sendo compreendido em Educação e nas Ciências Lingüísticas. Para Soares ${ }^{1}$, o significado do termo letramento referese ao "estado ou condição de quem não apenas sabe ler e escrever, mas cultiva e exerce práticas sociais que usam a escrita" (p. 47). O termo alfabetização tem sido empregado com o sentido mais restritivo de ação de ensinar a ler e escrever ${ }^{1}$.

De acordo com essa definição, uma pessoa alfabetizada, que sabe ler e escrever, pode não ser letrada, caso não faça uso da prática social de leitura, ou seja, não leia jornais, avisos, correspondências ou não escreva cartas e recados. Ao contrário, uma pessoa pode não ser alfabetizada, mas ser letrada, se tiver contato diário com as informações do mundo da leitura e da escrita, por meio de pessoas que lêem ou escrevem para elas as notícias do jornal, as cartas ou recados.

Segundo Soares ${ }^{1}$, as condições para o letramento estão relacionadas às condições socioeconômicas e culturais dos grupos sociais. O desenvolvimento da prática social da leitura e escrita depende de um processo real de escolarização e da disponibilidade de material de leitura.

Da mesma forma, podemos distinguir alfabetização de letramento em ciência e tecnologia. Nesse caso, consideramos que a alfabetização científica e tecnológica corresponderia ao processo escolar descontextualizado de nominalização restrita de determinados processos científicos e tecnológicos ou de resolução de exercícios e problemas escolares de ciências, muitas vezes desenvolvidos ritualisticamente por meio de algoritmos, sem uma compreensão conceitual mais ampla. Já o letramento em ciência e tecnologia seria o estado ou a condição de quem não apenas reconhece a linguagem científica e entende alguns de seus princípios básicos, mas cultiva e exerce práticas sociais que usam o conhecimento científico e tecnológico.

Em se tratando do nível da educação básica, utilizaremos o termo LCT com seu significado de função social. Essa função envolve a compreensão do impacto da ciência e da tecnologia sobre a sociedade $^{12}$. Tal dimensão tem um componente voltado para a compreensão pública da ciência e a formação de cidadãos para atuarem na atual sociedade científica e tecnológica.

Para desenvolver o LCT com função social, são requeridas as seguintes competências e habilidades: a leitura e compreensão da ciência; a expressão de opiniões sobre ciência; a preocupação com os problemas da ciência contemporânea, agora e para o futuro; participação nas tomadas de decisão democráticas; compreensão de como cência, tecnologia e sociedade se influenciam mutuamente $^{13}$. Esse letramento compreende a preparação para tomada de decisão, a qual corresponde a um dos objetivos centrais dos currículos com ênfase em CTS $^{14}$.
No Brasil, pouca atenção tem sido dada à educação tecnológica, que ficou restrita à educação técnica que marcou o sistema educacional brasileiro com duas vertentes: a propedêutica para a elite e a técnica para as classes populares. Mas recentemente, com o estabelecimento dos Parâmetros Curriculares Nacionais para o Ensino Médio ${ }^{15}$, foram adotados princípios curriculares que incorporam a tecnologia como componente curricular à qual foram acrescentadas as áreas de conhecimentos - Ciências da Natureza e suas Tecnologias e Ciências Humanas e suas Tecnologias.

E o que corresponderia a essa educação tecnológica? Na Lei de Diretrizes e Base da Educação Nacional de $1996^{16}$, houve a incorporação de princípios da educação tecnológica, buscando refletir a concepção de trabalho como princípio educativo ${ }^{17}$. Sem menosprezar a vertente sociológica, no presente artigo, discutiremos o conceito de letramento tecnológico, no sentido da contribuição específica do ensino de ciências nesse processo educativo.

Para Pacey ${ }^{18}$, a prática tecnológica é constituída pelos seguintes aspectos centrais que são ilustrados na Figura 2:

1. aspecto técnico: conhecimentos, habilidades e técnicas; instrumentos, ferramentas e máquinas; recursos humanos e materiais; matérias-primas, produtos obtidos, dejetos e resíduos;

2. aspecto organizacional: atividade econômica e industrial; atividade profissional dos engenheiros, técnicos e operários da produção; usuários e consumidores; sindicatos;

3. aspecto cultural: objetivos; sistema de valores e códigos éticos; crenças sobre progresso, consciência e criatividade.

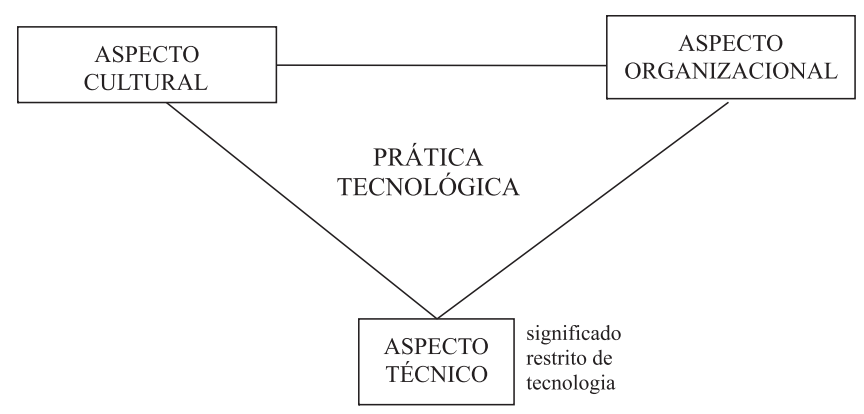

Figura 2. Aspectos envolvidos na prática tecnológica

Em geral, o sentido a que se reporta a educação tecnológica é o restrito que leva em conta apenas o aspecto técnico. Todavia, no letramento tecnológico, é fundamental a identificação dos aspectos organizacionais e culturais da tecnologia, os quais permitirão ao cidadão compreender como a tecnologia é dependente dos sistemas sociopolíticos e dos valores e ideologias da cultura em que está inserida.

Uma pessoa letrada tecnologicamente teria o poder e a liberdade de usar seus conhecimentos para examinar e questionar os temas de importância na sociotecnologia. Isso implica ser crítico no uso da tecnologia, ou seja, ter a habilidade intelectual de examinar os prós e contras de algum desenvolvimento tecnológico, examinar o potencial de seus benefícios e de seus custos e perceber o que estar por de trás das forças políticas e sociais que orientam esse desenvolvimento. Isso vai além do conhecimento técnico específico sobre o uso da tecnologia que também se torna importante no mundo atual dominado por tantos aparatos tecnológicos.

Na sociedade moderna, muitas vezes, os especialistas, tomam decisões sobre questões sociais, sem a participação dos cidadãos. Nesse contexto, o LCT do cidadão poderia contribuir na preparação dos alunos para compreenderem a opinião dos especialistas e participarem das decisões sociais. Como afirma Fourez ${ }^{19}$, 
"As pessoas poderiam, assim, ser consideradas cientifica e tecnologicamente letradas quando seu conhecimento e suas habilidades thes dão um certo grau de autonomia (a habilidade de ajustar suas decisões aos limites naturais ou sociais), uma certa habilidade para comunicar (selecionar o modo apropriado de expressão), e um certo grau de controle e responsabilidade no tratamento de problemas específicos (técnicos, mas também emocionais, sociais, éticos e culturais). Nessa visão, LCT não está preocupado somente com conhecimento científico e técnico, mas também com a participação na vida de uma sociedade que carrega a marca da tecnociência (p. 51) [tradução nossa]".

\section{GLOBALIZAÇÃo}

Ao se pensar em letramento para a cidadania planetária, se faz necessária uma reflexão sobre o processo de globalização que vem marcando drasticamente o modo de vida em nosso planeta. No último século, o desenvolvimento científico e tecnológico gerou novas formas de relações em diversos setores da sociedade, que estabeleceu uma nova ordem no mundo. Essa nova ordem possibilitou um aumento de qualidade e da expectativa de vida das sociedades industrializadas. Todavia, esse processo que iniciou com uma grande confiança na ciência e na tecnologia que trariam a esperança de uma vida melhor culminou, ao final do século passado, com uma visão temerária em relação às consequiências de seu desenvolvimento, que passou não só a trazer benefícios como também a ser fonte geradora de grandes riscos sociais. Bursztyn ${ }^{20}$ mostra a mudança desse cenário de expectativa em relação à visão de futuro sobre vários aspectos sociais no contexto mundial no Quadro 1.

Essa mudança se deu basicamente devido ao processo de globalização que se expandiu em todos os países, o qual mudou valores em todos os setores. Segundo Vieira ${ }^{21}$, houve uma reformulação do conceito clássico de soberania nacional e hegemonia, reduzindo o espaço Estado-nação. Hoje, as tomadas de decisões políticas e econômicas em qualquer país dependem do contexto global, o qual muitas vezes determina políticas contrárias ao interesse nacional. Essa interdependência das nações se deu em diversas esferas e ficou conhecida como globalização.

Apesar de, geralmente, a globalização estar mais associada a processos econômicos, está também relacionada a questões ambientais e culturais. O acidente nuclear de Chernobyl é um típico exemplo de como problemas locais rapidamente afetam grandes regiões do planeta.

Do ponto de vista cultural, ocorreu durante o século passado uma padronização de tipos culturais, influenciada principalmente pelos padrões cinematográficos impostos pela indústria de Hollywood, cuja distribuição de filmes atinge os lugares mais recônditos. Grandes redes de comunicação mundial padronizam as principais mensagens que são transmitidas igualmente para todos os países. Movimentos musicais, como o fenômeno dos Beatles, são difundidos rapidamente pela mídia e influenciam grupos em diversas partes do planeta.

Para Giddens ${ }^{22}$, globalização é a intensificação de relações sociais em escala mundial que ligam localidades distantes, de tal maneira que acontecimentos locais são modelados por eventos ocorrendo a milhares de quilômetros e vice-versa. Nesse contexto, vale destacar o que Santos ${ }^{23}$ diferencia do que se chama localismo globalizado e globalismo localizado. No localismo globalizado, o que se tem é a difusão de um padrão local que passa a ser incorporado em outras localidades diferentes, como o processo de globalização cultural e a atuação de empresas multinacionais nos diversos continentes. Já o globalismo localizado refere-se aos efeitos globais em determinados locais, como efeitos de poluição sofridos por uma região em decorrência de problemas causados em outras, como o efeito da chuva ácida provocada por indústrias poluentes de regiões vizinhas. Outro exemplo de globalismo localizado está na imposição de modelos econômicos por agências financeiras internacionais, que obrigam países a adotarem políticas locais segundo modelos transnacionais.

Como conseqüência da globalização, tivemos uma profunda mudança de valores. Houve um redimensionamento do espaço e tempo, de forma que, a qualquer momento, notícias são veiculadas ao vivo de fatos ocorridos no outro lado do planeta. Isso tornou o mundo uma grande aldeia em que todos podem saber o que está acontecendo em lugares distantes, como se fossem seu vizinho ao lado. Mas, com isso, houve uma ocidentalização do mundo com a expansão do capitalismo, implantando valores ocidentais de consumo até em países de culturas orientais. Outras mudanças ocorreram, como a descentralização da produção, em que a produção se efetiva em uma rede em que matérias-primas são extraídas de diferentes locais, são processadas em indústrias situadas em outras regiões e depois são globalmente distribuídas. No campo social, houve a fragmentação das grandes ideologias.

Percebe-se assim que a globalização tem ocorrido em diferentes campos. Dentre outras classificações das dimensões da globalização, podemos identificar as cinco propostas por Vieira ${ }^{21}$ : econômica, política, social, ambiental e cultural. A análise dessas dimensões nos apresenta um aspecto sombrio do processo. No campo econômico, Vieira ${ }^{21}$ destaca a influência do mercado financeiro, a criação de blocos regionais e a imposição de modelos econô-

Quadro 1. Visão de futuro. Adaptado da ref. 18

\begin{tabular}{|lll|}
\hline & Fim séc. XIX & Fim séc. XX \\
\hline Expectativa geral & otimismo & pessimismo \\
Papel da C \& T & $\begin{array}{l}\text { Forte crença na capacidade de } \\
\text { resolução de problemas }\end{array}$ & Desencanto e consciência da necessidade de precaução \\
Condições de vida & Perspectiva de bem-estar & Um mal-estar pelo agravamento de carências \\
Instância reguladora & Crescentemente o Estado & Crescentemente o mercado \\
Relação entre os povos & Paz & Guerras \\
Relação entre grupos sociais & Maior igualdade & Maior desigualdade \\
Economia & Forte crescimento & Crescimento lento, estagnação \\
Progresso & Promotor de riqueza & Causador de impactos ambientais \\
Mundo & Interdependência (mercados) e & Globalização e exclusão de regiões desnecessárias \\
\hline
\end{tabular}


micos pelos países mais ricos, que têm gerado graves consequiências sociais para os países mais pobres. $\mathrm{Na}$ dimensão política, Vieira $^{21}$ afirma que a reestruturação capitalista vem impondo uma nova ordem política mundial, em que os "Estados nacionais ficam privados da possibilidade de articular uma política autônoma de desenvolvimento" (p. 87). No campo social, a globalização vem levando a um processo crescente de desigualdade, conforme apontaremos mais adiante. Em relação ao ambiente, o que temos presenciado é o agravamento de problemas globais. Já em relação à dimensão cultural, o que se tem é um processo de mundialização da cultura de forma controvertida em que, ao mesmo tempo em que se padronizam valores, outros são fragmentados e descentralizados. A fase atual da globalização é caracterizada pela descentralização, segmentação, flexibilização e pelo pluralismo do mercado, valores que têm levado a um processo de "desencaixe" social em que segmentos sociais passam a incorporar valores de outros grupos culturais distantes, enquanto desconsideram grupos vizinhos que não se enquadram no seu circuito cultural ${ }^{21}$. Dessa forma, os ricos dos países pobres se afastam de seus vizinhos pobres e se aproximam dos ricos distantes; com isso, o que presenciamos é um processo de aproximação do distante e de distanciamento do próximo.

Essa análise da globalização tem gerado uma idéia bastante negativa a seu respeito que, freqüentemente, está associada a um processo pernicioso, a que muitos grupos ativistas combatem veementemente. Por outro lado, é possível uma análise desse processo com uma perspectiva diferenciada, em que se busquem novos valores, ou melhor, uma reversão do modelo vigente em que ao invés de se concentrar os benefícios esses fossem igualmente globalizados.

Nesse sentido, há necessidade de uma reorientação da globalização, para que gere efeitos positivos para todos os setores da população. Ela pode ser fonte de desenvolvimento econômico para muitos países, como foi para os chamados tigres asiáticos. Além do que, o processo instaurado implantou uma tamanha dominação que hoje não tem como ser revertida sem custos sociais maiores do que ela gerou. Com esse pensamento, tem-se defendido um movimento para criação de um novo modelo que leva, ao invés da exclusão social, à sua inclusão, o qual tem-se destacado por uma nova ordem: a da cidadania planetária. Essa será a via para a construção de um mundo solidário e pacífico.

\section{INCLUSÃO SOCIAL}

Em relação à pobreza, segundo dados do Banco Mundial, de uma população global estimada em 5,9 bilhões de indivíduos, em 1998, 2,8 bilhões, classificados como pobres, viviam com menos de 2 dólares por dia. Desses, 1,2 bilhão, considerados miseráveis, viviam com menos de 1 dólar por dia. Os pobres correspondem assim, a nada menos que $61 \%$ da população dos países subdesenvolvidos ou em desenvolvimento e os miseráveis, a 26\% - mais de um quarto do total da população mundial ${ }^{24}$.

O abismo entre ricos e pobres vem aumentando nos últimos anos. Enquanto, em 1990, a renda média dos $20 \%$ mais ricos do mundo era 60 vezes maior que a dos $20 \%$ mais pobres; em 1999 , essa renda passou a ser 74 vezes maior. Uma outra evidência gritante da diferença entre pobres e ricos está no fato de que os $10 \%$ mais ricos dos EUA recebem, sozinhos, o equivalente aos $47 \%$ mais pobres do planeta. Hoje, o $1 \%$ mais rico da população mundial tem renda equivalente à dos $57 \%$ mais pobres. O país menos desigual é o Japão, onde os $10 \%$ mais ricos recebem uma renda 4,5 vezes superior à dos $10 \%$ mais pobres. Nos EUA, essa diferença é de 16,6 vezes, enquanto na França é de 9,1 e, no Brasil, é de 65 vezes, o que corresponde ao mesmo valor do apurado para a África do $\mathrm{Sul}^{24}$.
O Brasil é o sexto país do mundo com a pior distribuição de renda, ficando atrás apenas de algumas nações africanas. Em 2001, os $50 \%$ mais pobres concentravam $14,8 \%$ da renda gerada no país, enquanto o $1 \%$ mais rico ficava com $13,3 \%$ da renda. Um terço da população brasileira encontra-se abaixo da linha de pobreza. Conforme os cálculos do Instituto de Pesquisa Econômica Aplicada IPEA, em 2003, o Brasil possuía cerca de 57,9 milhões de pessoas abaixo da linha de pobreza, o que representava $34,1 \%$ da população. Em 1993, 41,6\% da população estavam abaixo da linha de pobreza. De acordo com o último levantamento do IPEA, realizado em 2001, do total de pobres no país, $76 \%$ estão nas grandes metrópoles e áreas urbanas e apenas $24 \%$ vivem nas áreas rurais. Ainda segundo o IPEA, em 2001, o Brasil possuía 25,2 milhões (14,6\% da população brasileira) de indigentes (considera-se linha de indigência o nível de renda abaixo do qual as pessoas não conseguem satisfazer sequer as despesas de alimentação) ${ }^{25}$.

Em relação à situação do trabalho no Brasil, cerca de 22 milhões de pessoas recebem um valor equivalente ou inferior a um salário mínimo, o que representa 27,8\% do total de trabalhadores, conforme dados da Pesquisa Nacional por Amostra de Domicílios - PNAD - de 2003, desenvolvida pelo Instituto Brasileiro de Geografia e Estatística - IBGE. O rendimento médio da população ocupada no Brasil situa-se em torno de 2,5 salários mínimos para o país ${ }^{25}$.

Ainda segundo a PNAD/IBGE, 11,7\% (5 milhões) das crianças e adolescentes de 5 a 17 anos de idade trabalhavam em 2003, sendo que, em 1993, esse percentual era de $19 \%$. Na faixa de 5 a 14 anos, a pesquisa de 2003 revelou que 1,3 milhões de meninos e 609 mil meninas trabalhavam, principalmente em pequenos empreendimentos familiares, especialmente no setor agrícola, desenvolvendo trabalhos sem remuneração $0^{25}$.

As desigualdades sociais também se manifestam no mundo em relação às mulheres. Elas são menos privilegiadas no acesso ao ensino, representando quase dois terços da população mundial analfabeta $^{24}$. Em 2003, de acordo com a PNAD/IBGE, a taxa de desemprego feminino para o conjunto do Brasil era de $12,3 \%$, contra $7,8 \%$ na população masculina. As mulheres ocupam $41,5 \%$ dos empregos existentes e representam $54 \%$ do total de desempregados. O rendimento médio dos ocupados, em 2003, era de 722 reais para trabalhadores do sexo masculino e de 456 reais para os do sexo feminino, uma diferença de 58,3\%. Enquanto $24,4 \%$ dos homens recebem remuneração igual ou inferior ao salário mínimo, no caso das mulheres, esse percentual é de $32,5 \%{ }^{25}$.

Essa situação de desigualdade implica na necessidade da adoção de medidas que venham a superar esses abismos sociais, o que nos remete à educação em uma perspectiva de cidadania planetária. Ao mesmo tempo, isso tudo nos leva a refletir sobre que tipo de LCT almejamos para nossa sociedade tão desigual. Será o letramento em um modelo voltado para a elite que aumenta o fosso entre pobres e ricos, ou um modelo que busque a superação das desigualdades?

Como pensar em LCT em um país em que ainda tem índice elevado de analfabetismo, apesar do significativo avanço que teve durante todo o século XX, como demonstram os dados da Tabela 1? A diminuição crescente desse índice ainda não foi capaz de nos tirar da lista dos setes países latino-americanos que possuem taxa de analfabetismo superior a $10 \%$. Em termos de letramento, se tomarmos o conceito de analfabetismo funcional (pessoas acima de 15 anos que possuem menos de quatro anos de escolaridade e que são capazes apenas de localizar informações em enunciados de uma só frase), esse índice é muito pior, pois alcança o valor de $30 \%$ na faixa etária de 15 a 64 anos, chegando a $37 \%$ a taxa daqueles que só conseguem ler trechos curtos ${ }^{25}$. 
Tabela 1. Analfabetismo na faixa de 15 anos ou mais - Brasil $1900 / 2000$

\begin{tabular}{lrcc}
\hline Ano & \multicolumn{3}{c}{ População de 15 anos ou mais } \\
& Total $^{(1)}$ & Analfabeta $^{(1)}$ & $\begin{array}{c}\text { Taxa de } \\
\text { analfabetismo }^{\text {Tno }}\end{array}$ \\
\hline 1900 & 9.728 & 6.348 & 65,3 \\
1920 & 17.564 & 11.409 & 65,0 \\
1940 & 23.648 & 13.269 & 56,1 \\
1950 & 30.188 & 15.272 & 50,6 \\
1960 & 40.233 & 15.964 & 39,7 \\
1970 & 53.633 & 18.100 & 33,7 \\
1980 & 74.600 & 19.356 & 25,9 \\
1991 & 94.891 & 18.682 & 19,7 \\
2000 & 119.533 & 16.295 & 13,6 \\
\hline
\end{tabular}

Fonte: IBGE, Censo Demográfico. Nota: (1) Em milhares

Esse quadro do analfabetismo vem se alterando drasticamente nos últimos 10 anos, de forma que há expectativa de que nos próximos 50 anos venhamos a ter taxas bem baixas de analfabetismo, como se pode deduzir a partir da análise da Tabela 2. Observa-se que, em 1996, a taxa de analfabetismo era elevada até na faixa de 10 a 14 anos e que, em 2001, essa taxa foi reduzida à metade.

Hoje o ensino fundamental abrange 97\% dos brasileiros de 7 a 14 anos, índice considerado excelente por órgãos internacionais. Houve uma melhora significativa no fluxo escolar, fazendo com que mais alunos estejam conseguindo chegar às séries finais. As matrículas no ensino médio, em 1980, eram de 2,8 milhões, em 1999, de 7,7 milhões e, em 2004, de 9,1 milhões. Em 1980, cerca de 540 mil alunos terminaram a última etapa da educação básica, e, em 2002, foram 1,9 milhão. Diferentemente da educação superior, o aumento ocorreu praticamente todo na rede pública. Há duas décadas a rede pública absorvia cerca de $60 \%$ das matrículas, hoje

Tabela 2. Taxa de analfabetismo por faixa etária - Brasil - 1996/ 2001

\begin{tabular}{lrrc}
\hline Faixa etária & \multicolumn{3}{c}{ Ano } \\
& 1996 & 1998 & 2001 \\
\hline 10 a 14 & 8,3 & 6,9 & 4,2 \\
15 a 19 & 6,0 & 4,8 & 3,2 \\
20 a 29 & 7,6 & 6,9 & 6,0 \\
30 a 44 & 11,1 & 10,8 & 9,5 \\
45 a 59 & 21,9 & 20,1 & 17,6 \\
60 e mais & 37,4 & 35,9 & 34,0 \\
\hline
\end{tabular}

Fonte: IBGE, Pnads 1995, 1998 e 2001. Nota: Exclusive população rural de Rondônia, Acre, Amazonas, Roraima, Pará e Amapá. representa 88\%. Em 1980, dos concluintes do ensino médio, 44\% estudaram em escolas públicas ${ }^{25}$.

Deve-se, contudo, considerar que se houve uma grande expansão da rede escolar pública nos últimos 30 anos, isso por outro lado veio acompanhado por uma crescente queda da qualidade no nível de ensino dessas escolas. Dessa forma, o grande desafio educacional atual é pelo aumento da qualidade, pois apesar de termos alcançado maior democratização do acesso, continuamos com uma grande desigualdade na qualidade. Em outras palavras, o desafio está em melhorar o nível do letramento da população, pois continuamos com uma grande parcela da população escolarizada ainda sendo iletrada.

Isso pode ser demonstrado pelos dados de avaliação do sistema educacional. Segundo resultados do Sistema Nacional de Avaliação da Educação Básica - Saeb, a média nacional dos alunos está abaixo do nível considerado de proficiência ${ }^{26}$. Os resultados do Saeb quando expressos pela qualificação das habilidades revelam que menos de $10 \%$ dos alunos concluem as fases da educação básica com o nível adequado e mais de $50 \%$ concluem com níveis considerados críticos ou muito críticos a $4^{\mathrm{a}}$ série do ensino fundamental em Língua Portuguesa e Matemática, conforme a Tabela 3.

Os dados da Tabela 3 demonstram que, de modo geral, o desempenho dos alunos melhora na $8^{\mathrm{a}}$ série do ensino fundamental e no ensino médio, porém é ainda muito baixo em termos de letramento. Em Matemática, o percentual dos alunos nos estágios críticos e muito críticos continua acima de $50 \%$ e, em Língua Portuguesa, está acima de $25 \%$.

Os níveis críticos e muito críticos são patamares de muito pouco aprendizado, que caracterizam um estado de não letramento. Em Língua Portuguesa, considera-se como nível crítico, na $4^{\mathrm{a}}$ série do ensino fundamental, os alunos que constroem o entendimento de frases simples, sendo leitores ainda no nível primário, que decodificam apenas a superfície de narrativas simples e curtas, localizando informações explícitas. $\mathrm{Na} 8^{\mathrm{a}}$ série, considera-se nível crítico alunos que ainda não são bons leitores, possuem habilidades de leitura apenas para textos simples e textos informativos; e, na $3^{\text {a }}$ série do ensino médio, estão no nível crítico os alunos que lêem apenas textos narrativos e informativos simples. Em Matemática, considera-se como nível crítico, na $3^{\mathrm{a}}$ série do ensino médio, os alunos que desenvolveram algumas habilidades elementares de interpretação de problemas, mas não conseguem transpor o que está sendo pedido no enunciado para uma linguagem matemática específica.

O baixo desempenho dos alunos é mais acentuado nas escolas públicas, todavia, o desempenho nas escolas particulares também está aquém do desejado. Enquanto apenas 3,7\% dos alunos da rede pública tiveram desempenho considerado adequado em Português e 2,1\% em Matemática, os estudantes de escolas particulares nessas mesmas condições atingiram 27,6\%.

Se o desempenho dos alunos em Matemática está muito baixo, certamente não é muito diferente em Ciências. Os estudantes bra-

Tabela 3. Percentual de estudantes nos estágios de construção de competências em Língua Portuguesa e Matemática - $4^{\mathrm{a}}$ série ensino fundamental $(\mathrm{EF}), 8^{\mathrm{a}}$ série EF e $3^{\mathrm{a}}$ série ensino médio (EM) - Brasil - Saeb 2001 e 2003

\begin{tabular}{|c|c|c|c|c|c|c|c|c|c|c|c|c|}
\hline \multirow{3}{*}{ Estágio } & \multicolumn{6}{|c|}{ Língua Portuguesa } & \multicolumn{6}{|c|}{ Matemática } \\
\hline & \multicolumn{2}{|c|}{$4^{\mathrm{a}} \mathrm{EF}$} & \multicolumn{2}{|c|}{$8^{\mathrm{a}} \mathrm{EF}$} & \multicolumn{2}{|c|}{$3^{\mathrm{a}} \mathrm{EM}$} & \multicolumn{2}{|c|}{$4^{\mathrm{a}} \mathrm{EF}$} & \multicolumn{2}{|c|}{$8^{a} \mathrm{EF}$} & \multicolumn{2}{|c|}{$3^{\mathrm{a}} \mathrm{EM}$} \\
\hline & 2001 & 2003 & 2001 & 2003 & 2001 & 2003 & 2001 & 2003 & 2001 & 2003 & 2001 & 2003 \\
\hline Muito crítico & 22,2 & 18,7 & 4,9 & 4,8 & 4,9 & 3,9 & 12,5 & 11,5 & 6,7 & 7,3 & 4,8 & 6,5 \\
\hline Crítico & 36,8 & 36,7 & 20,1 & 22,0 & 37,2 & 34,7 & 39,8 & 40,1 & 51,7 & 49,8 & 62,6 & 62,3 \\
\hline Intermediário & 36,2 & 39,7 & 64,8 & 63,8 & 52,5 & 55,2 & 40,9 & 41,9 & 38,8 & 39,7 & 26,6 & 24,3 \\
\hline Adequado & 4,9 & 4,8 & 10,3 & 9,3 & 5,3 & 6,2 & 6,8 & 6,4 & 2,8 & 3,3 & 6,0 & 6,9 \\
\hline Total & 100 & 100 & 100 & 100 & 100 & 100 & 100 & 100 & 100 & 100 & 100 & 100 \\
\hline
\end{tabular}

Fonte: Saeb 2001 e 2003. 
sileiros tiveram, em 2003, o segundo pior desempenho em Ciências entre 41 países pesquisados pelo Programa Internacional de Avaliação de Alunos - Pisa $^{27}$. O Pisa é um programa de avaliação comparada, cuja principal finalidade é produzir indicadores sobre a efetividade dos sistemas educacionais, avaliando o desempenho de alunos na faixa dos 15 anos. Esse quadro parece que não tende a ser revertido se considerarmos a estimativa para o déficit de professores que foi feita em 2002, conforme demonstram a Tabela 4. De acordo com essa Tabela, a estimativa de professores que vão concluir a licenciatura em Física e Química é menor que a metade da estimativa de demanda para essas funções.

Os indicadores estatísticos de educação também demonstram que a educação é distribuída no Brasil de modo desigual, tanto em termos de acesso quanto de permanência na escola. Além disso, há no currículo escolar o predomínio de um monoculturalismo no qual o conhecimento é pensado na ótica adultocêntrica, masculina, branca, ocidental, cristã e heteronormativa. Nesse sentido, pensar em letramento da população brasileira significa pensar em ações que venham a romper com esse monoculturalismo, valorizando a pluralidade que existe em nossa sociedade para garantir o direito de todos à educação e à uma escola verdadeiramente democráti$\mathrm{ca}^{28}$. Pensar, portanto, nas desigualdades sociais existentes em nosso planeta, nos remete automaticamente a uma busca da inclusão social. Esse conceito tem se ampliado e aparece hoje associado ao conceito de sustentabilidade, com o qual configura um conceito ampliado de cidadania planetária.

\section{SUSTENTABILIDADE}

O conceito de desenvolvimento sustentável inicialmente foi introduzido na Assembléia Geral da Organização das Nações Unidas - ONU, em 1979. Esse conceito ficou associado ao desenvolvimento como um processo integral que inclui dimensões não só econômicas, mas também culturais, éticas, políticas, sociais e ambientais. Para se caracterizar melhor essas dimensões, muitos têm preferido o emprego da terminologia de desenvolvimento humano sustentável.

Um conceito muito difundido para desenvolvimento sustentável é o que foi expresso no relatório Brundtland da ONU, em 1987, intitulado "Nosso Futuro Comum", que o caracteriza como desenvolvimento que satisfaz as necessidades do presente sem colocar em risco as gerações futuras. Essa conceituação tem sido motivo de críticas por parte de movimentos ambientalistas, na medida em que passou a ser empregada por diferentes grupos como discurso que não tem o ambiente como o principal fim. O discurso do desenvolvimento sustentável passou a ser uma estratégia de grandes grupos econômicos para manter o modelo de desenvolvimento econômico com aceitação popular, mas dentro da lógica consumista que continua a explorar os recursos naturais, encoberto por um discurso de que essa exploração não é agressiva ao ambiente. Esse discurso passou a ter ainda um caráter ideológico bem diferenciado para grupos privilegiados que defendem a reserva de grandes áreas de lazer para seu bem-estar, sem se preocuparem com os problemas ambientais transferidos para regiões mais pobres. Em síntese, por de trás do discurso de desenvolvimento sustentável pode haver uma preocupação de manutenção de privilégios, em contraste com as necessidades humanas globais e com o ideal de inclusão social na perspectiva de cidadania planetária.

Devido a essas críticas, tem sido proposto o conceito de sociedade sustentável. Como menciona Vieira ${ }^{21}$, referindo-se ao trabalho de Diegues ${ }^{29}$,

\begin{abstract}
"o conceito de sociedade sustentável seria mais adequado, pois possibilita a cada sociedade definir seus padrões de produção e consumo, bem como seu nível de vida, a partir de sua cultura, de seu desenvolvimento histórico e de seu ambiente natural. Abandona-se o modelo insustentável das sociedades em favor da possibilidade de existência de uma diversidade de sociedades sustentáveis, baseadas no princípio das sustentabilidade ecológica, econômica, social e política" (p. 131).
\end{abstract}

Em uma perspectiva do que se tem chamado de ecopedagogia para cidadania planetária, as condições para o desenvolvimento sustentável ${ }^{30}$ implicam que ele seja economicamente factível, ecologicamente apropriado, socialmente justo, culturalmente eqüitativo, respeitoso e sem discriminação de gênero.

Nesse sentido, o conceito de sustentabilidade não se restringe à questão ambiental, todavia, o seu discurso partiu de um movimento ambientalista que nasceu, sobretudo, devido ao agravamento de problemas ambientais que marcaram a segunda metade do século passado.

$\mathrm{O}$ uso indiscriminado de inseticidas que foi denunciado por Carson $^{31}$ em seu livro "Primavera Silenciosa", um dos primeiros manifestos ambientalistas, a ocorrência de uma série de desastres ambientais, assim como o relatório do Clube de Roma, preparado por cientistas e intitulado "Limites do Crescimento" contribuíram para o fortalecimento do movimento ambientalista.

Grandes acidentes ficaram conhecidos no mundo inteiro, como a contaminação por mercúrio da Baía de Minamata, no Japão, provocada por indústrias de fertilizantes e detectada em 1953, que teve registro oficial de mais de 1 mil óbitos, dentre mais de 12 mil pessoas que alegam terem sido contaminadas. Na Itália, em 1976, em

Tabela 4. Demanda estimada de funções docentes e número de licenciados por disciplina - Brasil

\begin{tabular}{|c|c|c|c|c|c|}
\hline \multirow[t]{2}{*}{ Disciplina } & \multicolumn{3}{|c|}{ Demanda estimada para 2002} & \multicolumn{2}{|c|}{ Número de licenciados } \\
\hline & Ensino Médio & Ensino Fund. $5^{\mathrm{a}}$ a $8^{\mathrm{a}}$ série & Total & 1990-2001 & $2002-2010^{(1)}$ \\
\hline Língua Portuguesa & 47.027 & 95.132 & 142.179 & 52.829 & 221.981 \\
\hline Matemática & 35.270 & 71.364 & 106.634 & 55.334 & 162.741 \\
\hline Biologia & 23.514 & 95.152 & 55.231 & 53.294 & 126.488 \\
\hline Física & 23.514 & (Ciências) & 55.231 & 7.216 & 14.247 \\
\hline Química & 23.514 & & 55.231 & 13.559 & 25.397 \\
\hline Língua Estrangeira & 11.754 & 45.576 & 59.333 & 38.410 & 219.617 \\
\hline Educação Física & 11.754 & 45.576 & 59.333 & 76.666 & 84.916 \\
\hline Educação Artística & 11.754 & 23.788 & 35.545 & 31.464 & 12.400 \\
\hline História & 23.514 & 47.576 & 71.089 & 74.666 & 102.602 \\
\hline Geografia & 23.514 & 47.576 & 71.089 & 53.509 & 89.121 \\
\hline
\end{tabular}

FonteMEC/Inep. Nota: (1) Dados estimados. 
Seveso, o vazamento acidental de indústria de herbicida de dioxina, substância altamente cancerígena, provocou a evacuação de centenas de habitantes da localidade e depois gerou um grande debate sobre o destino dos tonéis com o lixo tóxico resultante. Outro grande acidente foi o vazamento de isocianato de metila, em 1984, em Bophal na Índia, que matou 2.800 pessoas e deixou aproximadamente 200.000 feridos. O incêndio na fábrica da Sandoz, na Basiléia (Suíça), em 1986, abalou a confiança da população européia na indústria química, devido à grande quantidade de explosões e de produtos queimados, produzindo nuvens tóxicas que ameaçaram 400 mil pessoas. No acidente, a água usada para apagar o incêndio dissolveu e arrastou para o rio Reno $30 \mathrm{t}$ de produtos químicos, principalmente agrotóxicos, matando a população aquática do rio em uma grande extensão, incluindo países vizinhos. Ainda em 1986, o acidente nuclear de Chernobyl obrigou a evacuação de 135 mil pessoas da cidade e contaminou $75 \%$ da Europa.

A dramaticidade desses acidentes torna-se ainda maior quando se avalia que seus efeitos devastadores incidem principalmente nas populações mais pobres. Dados têm demonstrado que há uma desigualdade no planeta na distribuição dos geradores de poluição ambiental e dos que sofrem suas conseqüências. Como exemplo dessa desigualdade, Vieira ${ }^{19}$ cita que $20 \%$ da população mundial consomem $80 \%$ da energia e emitem 75 a $80 \%$ de gases do efeito estufa, que os americanos (295 milhões em 2005) poluem mais que os chineses (1,3 bilhões em 2005), além de consumirem 1/3 da energia do planeta. Dados de 1996 revelavam que 170 milhões de pessoas nas cidades e 885 milhões no campo não possuíam água potável $^{21}$.

Toda essa problemática tem produzido sem dúvida nenhuma efeitos no processo produtivo que, segundo Wongtschowski ${ }^{32}$, tem levado a uma mudança de postura das indústrias químicas. Em seu livro "Indústria Química", Wongtschowski ${ }^{32}$ apresenta dados sobre essas mudanças, como a de que o registro de ingredientes ativos de biocidas nos EUA foi reduzido de 1.600 em 1976 para 400 em 1993. Ainda segundo ele, houve um declínio de produção de produtos químicos por razões ambientais, com uma variação de 42 a $76 \%$ no período de cerca de 20 anos. Cita ainda que nos EUA, enquanto a produção de produtos químicos dobrou de 1970 a 1993, as emissões de poluentes e o consumo de energia foram reduzidos a $25 \%$.

Esses dados demonstram que tem ocorrido uma adesão da indústria ao programa de ação responsável e tem havido um aumento de investimentos na área ambiental. Essa preocupação, todavia, é mais em função das pressões populares e da legislação ambiental que em função de uma consciência ambiental. Conforme aponta Wongtschowski ${ }^{32}$, estudos sobre 15.000 fábricas em 80 países, de 1960 a 1988, demonstram o deslocamento de indústrias de poluição intensiva de países ricos para países pobres e que apenas 35\% da indústria americana instalada no México cumpre a legislação ambiental ${ }^{32}$.

Como conseqüência, a opinião pública mundial continua tendo uma imagem muito negativa da Química. Nesse sentido, os químicos têm um papel muito importante tanto no esforço de mostrar a necessidade dos empresários mudarem sua atitude em relação ao meio ambiente, como de demonstrar para a população os resultados positivos que temos alcançado com o avanço das pesquisas em Química verde.

Segundo Mozeto $^{33}$, a preocupação ambiental no Brasil, dos cidadãos, das empresas e dos químicos com relação aos problemas vinculados às atividades humanas tem sido crescente. Afirma Mozeto $^{33}$ que "um olhar sobre a evolução histórica da Química Ambiental mostra que a mesma ocupa hoje um cenário de grande destaque na vida científica do Brasil, além de ter conseguido uma projeção internacional que poucas áreas da Química conseguiram" (p. 10). Desde a década de 1980, vêm sendo criadas disciplinas de Química Ambiental em diversos Institutos de Química e têm sido produzidos vários artigos que estão contribuindo significativamente para que os professores possam dispor de informações químicas necessárias para tratar da educação ambiental.

\section{CIDADANIA PLANETÁRIA E ECOPEDAGOGIA}

O entendimento das desigualdades sociais mundiais e a visão ambiental com uma perspectiva global levaram ao desenvolvimento de uma visão unificadora do planeta e de sua população. Essa visão se expressa em um conjunto de princípios, valores e atitudes que passam a considerar a Terra como uma única comunidade, visão que remete à expressão cidadania planetária ${ }^{30,34-37}$.

A cidadania planetária remete a uma visão unificadora do planeta e de uma sociedade mundial. Essa visão rompe com a visão etnocêntrica ocidental e com os valores impostos pelo processo de globalização, que têm aumentado as desigualdades sociais. Ao contrário, pensar em cidadania planetária significa desenvolver valores cooperativos, de inclusividade, reciprocidade e complementaridade.

Isso se configura dentro de um novo paradigma, que vem sendo caracterizado por Morin ${ }^{37}$ como paradigma da complexidade. Propondo uma nova visão do conhecimento, Morin ${ }^{38}$ discute pressupostos de uma educação para o futuro, na qual deveria haver a substituição da visão de saberes desunidos, divididos, compartimentados pela visão multidisciplinar, transversal, multidimensional, transnacional, global e planetária. Para isso, a educação deveria tornar evidente no conhecimento seu contexto, o global, o mutidimensional e o complexo. Com essa perspectiva, a educação para cidadania planetária implicaria em uma discussão dos conhecimentos por meio da relação entre o todo e as partes em suas multidimensões (histórica, econômica, sociológica, religiosa...) dentro de unidades complexas, em que seus elementos são vistos como inseparáveis e constitutivos da totalidade ${ }^{38}$. Nessa visão, Morin ${ }^{38}$ considera ainda que há um tecido interdependente e inter-retroativo entre o objeto do conhecimento e seu contexto.

Para Gadotti ${ }^{36}$, o paradigma da complexidade caracteriza o movimento da ecopedagogia que, segundo ele, se fundamenta na diversidade e independência da vida; na preocupação comum da humanidade de viver com todos os seres do planeta; no respeito aos Direitos Humanos; nos valores da sustentabilidade; na justiça, eqüidade e comunidade; e na prevenção do que pode causar danos.

A ecopedagogia é um movimento social e político, que não se restringe à educação escolar, que teve origem na sociedade civil, por meio da constituição de Organizações Não-Governamentais ONGs.

Fazendo um histórico do conceito de cidadania e discutindo a crise da cidadania moderna, Vieira ${ }^{21}$ demonstra como o contexto das sociedades modernas levou ao surgimento de uma nova organização da sociedade civil, caracterizada pelos movimentos sociais e pelas ONGs. Essa sociedade passa a ter um papel importante no movimento de defesa dos interesses globais, o que vem sendo reconhecido por vários organismos internacionais. Nessa perspectiva, a cidadania planetária corresponde a valores que politicamente passam a ser defendidos por entidades do chamado terceiro setor, o qual a cada dia vem recebendo mais recursos e tem produzido diversas ações com resultados sociais importantes.

É nesse novo contexto que a ecopedagogia não se restringe ao movimento escolar e é nele que as Sociedades de Química passam também a ter um importante papel no processo de defesa do ambiente. Cabe aos químicos, enquanto cidadãos do planeta, atitudes engajadas em associações que venham a exigir investimentos governamentais e ações empresariais em que o conhecimento quími- 
co seja posto em benefício da construção de uma sociedade mais justa e igualitária.

\section{LCT NA PERSPECTIVA HUMANÍSTICA}

Ao pensarmos em uma proposta de letramento científico e tecnológico para a cidadania planetária, se faz necessário um entendimento de todos os processos até aqui discutidos, como a globalização, a inclusão social, a sustentabilidade e a ecopedagogia. A partir daí, podemos pensar em ações que a comunidade química precisa se comprometer.

No livro "Educação em Química: compromisso com a cidadania"12 defendemos a necessidade da educação para o cidadão englobar atitudes e valores a partir do conhecimento químico. Afirmamos que formar cidadãos implica em preparar o indivíduo para participar em uma sociedade democrática, por meio da garantia de seus direitos e do compromisso de seus deveres. Isso passa por desenvolver tanto a capacidade de fazer julgamento crítico como a de fazer julgamento político. O primeiro tipo de julgamento fundamenta-se em critérios estabelecidos universalmente como o julgamento jurídico (Estado de Direito) e o julgamento moral (Direitos Humanos), já o julgamento político fundamenta-se em critérios que visam ajustar os interesses particulares aos interesses gerais, em que o possível encaminhamento da solução dos problemas é dado pela discussão da pluralidade de idéias ${ }^{39}$. Assim, consideramos que a educação do juízo político é, fundamentalmente, uma educação para a discussão.

A discussão de valores passa pelo entendimento de que no mundo globalizado caracterizado pela exclusão, os valores predominantes não são os da cidadania planetária. Conforme demonstra Ferreira $^{40}$, na sociedade capitalista, se amesquinham a solidariedade, a fraternidade e a reciprocidade; a ajuda ao próximo deixa de ser desinteressada, pois deve render dividendos; a reciprocidade transforma-se em troca de favores que podem ser cobrados a qualquer momento e, nessa corrida de quem consegue acumular mais, desaparece a fraternidade.

Em nossos estudos sobre o letramento científico e tecnológico ${ }^{41}$, temos apontado um outro foco no sentido de (re)significação da função social desse processo. A partir da proposta educacional de Paulo Freire, temos concebido a função social de LCT na perspectiva humanística, a qual visa não só o desenvolvimento de competências para participar da sociedade, mas o desenvolvimento de atitudes e valores para uma cidadania planetária, comprometida com a construção de uma sociedade científica e tecnológica, fundamentada em valores humanos, que preservem a vida em escala mundial.

Segundo Freire ${ }^{42}$, a educação deveria ir muito além da repetição, constituindo-se em instrumento de libertação, de superação das condições sociais vigentes. Como afirmava: "Ninguém educa ninguém, ninguém educa a si mesmo, os homens se educam entre si, mediatizados pelo mundo" ${ }^{42}$ (p. 68). Essa mediatização ocorre por meio de uma educação problematizadora, de caráter reflexivo, de desvelamento da realidade, na qual o diálogo começaria a partir da reflexão das contradições básicas da situação existencial. É nessa reflexão que o diálogo permite a educação para a prática da liberdade.

A proposta de Freire é uma nova forma de práxis educativa, que em vez de reproduzir o mundo vai transformá-lo. As palavras geradoras, repletas de sentido para os educandos, são instrumentos de repensar o mundo. Nesse sentido, a proposta é de uma educação para a conscientização, que vai além do ato de ensinar a ler e escrever. $\mathrm{O}$ educando usaria a leitura e a escrita para desencadear um processo social de transformação de sua realidade.

Para ser coerente com a proposta de Paulo Freire, o letramento científico teria por objetivo a problematização de temas sociais, de modo a assegurar um comprometimento social dos educandos. Assim, o processo de letramento científico e tecnológico na educação básica deveria levar em consideração o contexto da sociedade tecnológica atual. Esse contexto é caracterizado de forma geral por um processo de dominação dos sistemas tecnológicos que impõem valores culturais e oferecem riscos à vida humana. No caso do Brasil e dos países do chamado terceiro mundo, ele é caracterizado por um processo de exclusão social em que apenas uma parcela da população usufrui seus benefícios, enquanto a maioria fica na marginalidade. Na perspectiva global, ele é caracterizado pela divisão desigual do trabalho, do lucro e da exploração ambiental. Enquanto aos países pobres são destinados os serviços produtivos de extração de matéria-prima com exploração de mão-de-obra e dos recursos naturais, aos países ricos é destinado o acúmulo de bens, de serviços e do lucro do controle da alta tecnologia e do capital sob a custa dos marginalizados e excluídos.

Isso implica uma concepção de letramento científico em que valores e atitudes sejam discutidos, na perspectiva de os alunos compreenderem o mundo tecnológico em que estão inseridos e poderem transformá-lo com base nos valores humanos. A mediação das questões relativas à ciência e tecnologia, nesse sentido, poderia ser desenvolvida a partir do que estamos denominando de aspectos sociocientíficos, ASC, ou seja, de questões ambientais, políticas, econômicas, éticas, sociais e culturais relativas à ciência e tecnologia ${ }^{37}$.

É com essa perspectiva que temos desenvolvido o Projeto Ensino de Química e Sociedade - PEQUIS, no qual produzimos materiais didáticos para o ensino médio de Química ${ }^{43}$. Com esses materiais, procuramos por meio da contextualização temática desenvolver valores e atitudes comprometidos com a cidadania ${ }^{44}$. Ao tratar dos conteúdos químicos os associamos com temas sociais e ao abordar esses temas discutimos aspectos sociais, econômicos, ambientais e éticos. Introduzimos no livro "Química e Sociedade" ${ }^{43}$ discussões sobre problemas ambientais como lixo urbano, poluição atmosférica, uso de agrotóxicos, poluição das águas, medidas para evitar desperdício de água e de energia, descarte de resíduos sólidos e uso dos transgênicos. Em diversos textos, introduzimos discussões sobre as desigualdades sociais no Brasil e no mundo, apresentando o problema do trabalho infantil em lixões, o problema do acesso à tecnologia, a má distribuição de alimentos, a fome que atinge boa parte da população mundial. O papel da tecnologia é exaustivamente trabalhado no livro, incluindo aí discussões sobre o papel das indústrias químicas. Além disso, em toda a obra há sempre textos discutindo os diferentes significados de desenvolvimento sustentável e sugestões de atividades de ações de cidadania, visando engajar os estudantes em movimentos sociais.

\section{CONSIDERAÇÕES FINAIS}

No século que iniciou com terrorismos de grupos radicais e de grandes potências que invadem países desrespeitando organismos internacionais, não podemos nos eximir do debate dessas questões. Pensar em letramento em Química, educação planetária e inclusão social implica em incluir nos cursos de graduação de Química e nos debates das associações de Química, como o promovido pela SBQ em sua Reunião Anual de 2005, discussões sobre o papel do químico no processo de construção de uma sociedade mais igualitária. A comunidade de químicos também tem grande responsabilidade no processo de letramento científico e tecnológico da população em geral. Isso exige um comprometimento de seus profissionais em ações políticas por meio de suas associações, buscando conscientizar governo e empresários a adotarem medidas em que o conhecimento químico seja colocado em favor da vida de 
todos os habitantes de nosso planeta, de forma que seus benefícios sejam estendidos ao maior número de pessoas. Dessa forma, estaremos contribuindo para a formação de uma imagem mais positiva da Química junto ao público em geral e colaborando para a construção de uma sociedade mais justa e igualitária.

\section{AGRADECIMENTOS}

Ao Fundo de Pesquisa do Decanato de Pós-Graduação da Universidade de Brasília - DPP/UnB e ao CNPq pelo apoio material e financeiro ao projetos de pesquisa que desenvolvemos, que deram suporte ao presente artigo.

\section{REFERÊNCIAS}

1. Soares, M.: Letramento: um tema em três gêneros, Autêntica: Belo Horizonte, 1998.

2. Laugksch, R. C.; Science Education 2000, 84, 71.

3. Millar, R.; School Science Review 1996, 280, 7.

4. Ratcliffe, M.; Grace, M.; Science education for citizenship: teaching socioscientific issues, Open University Press: Maidenhead, 2003.

5. Krasilchick, M.; O professor e o currículo das ciências, EDUSP: São Paulo, 1987.

6. Waks, L. J. Em Ciencia, tecnología y sociedad: estudios interdisciplinares en la univeridade, en la educacíon y en la gestión política y social; Medina, M.; Sanmartín, J., eds.; Anthropos: Barcelona; Universidad del País Vasco: Leioa (Vizcaya), 1990.

7. Shamos, M. H.; The myth of scientific literacy, Rutgers University Press: New Brunswick, 1995.

8. Miller, J. D.; Daedalus: Journal of the American Academy of Arts and Sciences 1983, 112, 29.

9. DeBoer, G. E.; Journal of Research in Science Teaching 2000, 37, 582.

10. Shen, B. S. P.; American Scientist 1975, 63, 265.

11. Prewitt, K.; Daedalus: Journal of the American Academy of Arts and Sciences 1983, 112, 49.

12. Santos, W. L. P. dos; Schnetzler, R. P.; Educação em química: compromisso com a cidadania, Ed. da Unijuí: Ijuí, 1997.

13. Solomon, J.; School Science Review 2001, 300, 93.

14. Santos, W. L. P. dos; Mortimer, E. F.; Ensaio - pesquisa em educação em ciências 2000, 2, 133.

15. Brasil. Ministério da Educação - MEC, Secretaria de Educação Média e Tecnológica - Semtec; Parâmetros Curriculares Nacionais para o Ensino Médio, MEC/Semtec: Brasília, 1999.

16. Brasil; Lei de Diretrizes e Bases da Educação Nacional, Lei $n^{\circ} 9394$ de 20 de dezembro de 1996.
17. Kuenzer, A. Z.; Ensino de $2^{\circ}$ grau: o trabalho como princípio educativo, Cortez: São Paulo, 1988.

18. Pacey, A.; La cultura de la tecnología, Fondo de Cultura Económica: Cidade do México, 1990.

19. Fourez, G. Em Innovations in science and technology education; Jenkins, E., ed.; UNESCO Publishing: Paris, 1997, vol. VI, p. 43-57.

20. Bursztyn, M. Em Ciência, ética e sustentabilidade: desafios ao novo século; Bursztyn, M., org., Cortez: São Paulo; UNESCO: Brasília, 2001, p. 9-20.

21. Vieira, L.; Cidadania e globalização, Record: Rio de Janeiro, 1997.

22. Giddens, A.; The consequences of Modernity, Standford University Press: Stanford, 1991.

23. Santos, B. S.; Toward a new common sense: law, science and politics in the paradigmatic transition, Routledge: New York, 1995.

24. Almanaque Abril; Mundo 2005, Ed. Abril: São Paulo, 2005.

25. Almanaque Abril; Brasil 2005, Ed. Abril: São Paulo, 2005.

26. Brasil; Ministério da Educação - MEC, Instituto Nacional de Estudos e Pesquisas Educacionais Anísio Teixeira - Inep. Resultados do Saeb 2003, MEC/Inep: Brasília, 2004.

27. http://www.oecdbookshop.org/oecd, acessada em Maio 2005.

28. Brasil; Ministério da Educação - MEC, Secretaria de Educação Continuada, Alfabetização e Diversidade - Secad; Unidade na Diversidade e a Revisão dos PCN do Ensino Médio, MEC/Secad: Brasília, mimeo, 2005.

29. Diegues, A. C.; Ecologia humana e Planejamento em Áreas Costeiras, Nupaub: São Paulo, 1995.

30. Gutiérrez, F.; Prado, C.; Ecopedagogia e cidadania planetária, Cortez: São Paulo, 1999.

31. Carson, R.; Silent Spring, Penguin Books: London, 1965.

32. Wongtschowski, P.; Indústria química, Ed. Edgard Blücher Ltda: São Paulo, 1999.

33. Mozeto, A. A; Jardim, W. de F.; Quim. Nova 2002, 25 Supl. 1, 7.

34. Boff, L.; Nova era: a civilização planetária, Ática: São Paulo, 1994.

35. Boff, L.; Ecologia: grito da Terra, grito dos pobres, Ática: São Paulo, 1995.

36. Gadotti, M.; Pedagogia da terra, Petrópolis: São Paulo, 2000.

37. Morin, E.; Introdução ao pensamento complexo, $3^{\mathrm{a}}$ ed., Instituto Piaget: Lisboa, 2001.

38. Morin, E.; Os sete saberes necessários à educação do futuro, Cortez: São Paulo; Unesco: Brasília, 2000.

39. Canivez, P.; Educar o cidadão?, Papirus: Campinas, 1991.

40. Ferreira, N. T.; Cidadania: uma questão para a educação, Nova Fronteira: Rio de Janeiro, 1993.

41. Santos, W. L. P. dos; Tese de Doutorado, Universidade Federal de Minas Gerais, Brasil, 2002.

42. Freire, P.; Pedagogia do oprimido, Paz e Terra: Rio de Janeiro, 1972.

43. Santos, W. L. P. dos; Mól, G. de S., coords.; Química e Sociedade, Nova Geração: São Paulo, 2005.

44. Santos, W. L. P. dos; Mól, G. de S.; Silva, R. R. da; Castro, E. N. F de; Silva, G. de S; Matsunaga, R. T.; Farias, S. B.; Santos, S. M. de O.; e Dib, S. M. F; Química Nova na Escola 2004, no. 20, 11. 